\title{
A TEORIA POLÍTICA DE JOÃO WYCLIF
}

Jürgen Miethke ${ }^{* *}$

SÍNTESE - o decorrer século XIV, o conflito entre o papa e o imperador se esvaiu. Entrementes, os novos estados criavam corpo e os antigos problemas adquiriam nova roupagem. Esse foi o ambiente em que viveu Wyclif. Seu pensamento político possui uma matriz religiosa e sua intenção maior foi a de compreender a Igreja como comunidade de redimidos. Nessa condição ela só é conhecida por Deus e só no juízo final os homens saberão quem pertenceu à verdadeira Igreja. Baseado em Egídio Romano, mas lendo-o em outra clave, justifica a propriedade e o poder através do estado de graça. Em suas críticas à Igreja foi um dos antecessores da Reforma.

PALAVRAS-CHAVE - Novos estados. Igreja dos redimidos. Propriedade. Poder. Reforma.
ABSTRACT - During the XIV century, the conflict between the pope and the emperor lost force. In the meanwhile, the new states took body and the ancient problems took on new clothes. That was the environment in which Wyclif lived. His political thought owns a religious source, and his major intention was to understand the Church as a community of the redeemed. In such a condition the Church is only known by God, and only in the final judgment men will know who belonged to the true Church. Based on Giles of Rom, but reading him from a different point of view, he justifies property and power through the state of grace. In his critics to the Church he was one of the antecessors of the Reform.

KEY WORDS - New states. Church of the redeemed. Property. Power. Reform.

Durante o século XIV, a teoria política foi confrontada com uma nova situação. Antes deste século, os principais temas, para os teóricos, foram tomados ou dos embates entre o mundo espiritual e o secular, sobretudo da luta entre papa e imperador, ou do "espelho dos príncipes" regional, ${ }^{1}$ príncipes esses que estavam em busca de um controle ético da posição dominadora de governante no seu reino, dando continuidade a uma tradição muito antiga, oriunda dos tempos carolíngios. Com o advento do século XIV, a paisagem política na Europa tinha mudado consideravelmente. Os reinos nacionais da Europa Ocidental, especialmente a França e a Inglaterra, mas também os reinos ibéricos de Aragão e de Castela, estavam definitivamente procurando os seus próprios caminhos. Portanto, nas

\footnotetext{
Universidade de Heidelberg, Alemanha.

Fundamental continua sendo o estudo clássico de Wilhelm Berges, Die Fürstenspiegel des späten Mittelalters (MGH, Schriften 2), Leipzig 1939 [Neudruck Stuttgart 1952 u.ö.]; em breve, também Jürgen Miethke, Politische Theorien, in: Grundriss der Geschichte der Philosophie, begründet von Friedrich Ueberweg, hrsg. von Peter Schulthess und Ruedi Imbach: Das 13. Jahrhundert, hrsg. von Peter Schulthess und Christoph Flüeler, Basel [previsto para 2006], § 57 (com bibliografia).
}

\begin{tabular}{|l|l|l|l|l|l|}
\hline VERITAS & Porto Alegre & v. 51 & n. 3 & Setembro 2006 & p. 129-144 \\
\hline
\end{tabular}


diferentes regiões da Europa, havia também problemas com especificação regional, que eram abordados, pelos intelectuais nas várias universidades ${ }^{2}$ e nas cortes dos reis, em tratados mais ou menos extensos.

Bem no início do século XIV, o conflito entre o Papa Bonifácio VIII e o Rei Filipe, o Belo, havia marcado o nascimento de uma nova era na história da Europa. ${ }^{3}$ Foi com grande demora que esse conflito foi suavizado pelos sucessores de Bonifácio VIII. Passaram-se dez anos dos episódios que causaram o fim da vida de Bonifácio e do seu pontificado, até que uma primeira reestruturação tivesse sido feita. O Concílio de Viena terminou com uma nova concordância entre o papa e o rei. Pouco tempo antes, a corte papal havia sido transferida para as cercanias do reino francês. Desde 1309, o papa tinha a sua residência em Avinhão, ${ }^{4}$ onde os papas do século XIV tiveram de permanecer por cerca de quase cem anos, até 1404, sob a influência, às vezes mesmo sob a pressão, da corte do rei francês.

Isso não se sucedeu, absolutamente, sem sérias conseqüências para a corte papal e para a estrutura toda da cristandade européia. Não temos, aqui, qualquer pretensão de oferecer um quadro compreensivo dessas conseqüências, que tornaram toda a época do "papado de Avinhão" uma época realmente especial para a história da Igreja Medieval. Já o reformador alemão Martinho Lutero, no início do século XVI, chamou esta época de "o cativeiro babilônico" da Igreja ${ }^{5}$ - os historiadores alemães, até hoje, se inclinam a repetir esse juízo, mesmo que por meio de raciocínios diferentes, enquanto a historiografia francesa, por sua vez, se inclina a ver nestas décadas da "corte papal em Avignon" um dos verdadeiros pontos altos na história do papado como um todo. ${ }^{6}$ Não pretendo decidir sobre essa questão, aqui, mas podemos certamente concordar que as novas circunstâncias da convivência de tantas pessoas num local reduzido, em verdade sem o preparo necessá-

Agora, a nova exposição geral sobre as universidades da Europa pode ser conferida: A History of the University in Europe, ed. Walter Rüegg, vol. I: Universities in the Middle Ages, ed. Hilde de Ridder-Symoens, Cambridge (U.K.)-New York 1992 [= (versão alemã): Geschichte der Universität in Europa, hrsg. von Walter Rüegg, Bd. I: Mittelalter, München 1993]. Sobre Oxford: The History of the University of Oxford, vol. II: Late Medieval Oxford, ed. Jeremy I. Catto, Ralph Evans, Oxford 1992 (sobre Wyclif, cf. William J. Courtenay, Theology and Theologians from Ockham to Wyclif, p. 1-34; e Jeremy I. Catto, Wyclif and Wyclifitism at Oxford, 1356-1430, p. 175-261).

Sobre isso Jürgen Miethke, De potestate papae. Die päpstliche Amtskompetenz im Widerstreit der politischen Theorie von Thomas von Aquin bis Wilhelm von Ockham (Spätmittelalter und Reformation, Neue Reihe 16), Tübingen 2000 [= Ai confini del potere. Il dibatito sulla potestas papale da Tommaso d'Aquino a Guglielmo d'Ockham, traduzione di Cinzia Storti, prefazione, consulenza e revisione di Roberto Lambertini (Fonti e ricerche, 19), Padova 2005].

4 Cf., por exemplo, Handbuch der Kirchengeschichte, hrsg. Hubert Jedin, Bd.III/2: Die mittelalterliche Kirche. Vom Hochmittelalter bis zum Vorabend der Reformation (von Hans-Georg Beck, Karl August Fink, Josef Glazik, Erwin Iserloh, Hans Wolter), Freiburg 1968; Die Zeit der Zerreißproben (12741449), hrsg. Michel Mollat, André Vauchez, bearb. von Bernhard Schimmelpfennig (Die Geschichte des Christentums, Religion, Politik, Kultur, hrsg. Jean-marie Mayeur, Charles Pietri, André Vauchez, Marc Venard, em versão alemã hrsg. Norbert Brox, Odilo Engels, Georg Kretschmar, Kurt Meier, Heribert Smolinsky, Bd.6) Freiburg/Basel/Wien 1991.

5 Martin Luther, De captivitate Babylonica ecclesiae [Do cativeiro babilônico da Igreja], um dos mais famosos escritos polêmicos do ano de 1520.

6 Cf. a exposição sintética de Bernard Guillemain, La cour pontificale d'Avignon, 1309-1376 (Bibliothèque de l'École Française d'Athènes et de Rome, 201), Paris 1962. 
rio, causaram grandes problemas, respectivos a habilidades organizacionais e, especialmente, "logísticas".

De fato, possuímos um testemunho aparentemente inócuo sobre isso nos curiosos problemas em organizar a situação financeira de tantos membros da corte papal e em oferecer-lhes um salário suficiente, que, por um lado, tinha de estar suficientemente de acordo com a sua posição e, por outro, ser correspondente aos seus próprios sentimentos de dignidade. Por séculos afora, até antes desses eventos, a Igreja Romana tinha provido os cardeais ${ }^{8}$ e os clérigos da vasta corte papal com os meios financeiros necessários. As dioceses ao redor de Roma, as assim chamadas dioceses "suburbicárias", estavam incluídas nessa tarefa desde a Antiguidade Tardia, e permaneciam ainda na Idade Média Tardia como as prebendas dos bispos cardeais. Agora, porém, em Avinhão, todas as prebendas romanas na prática tinham se tornado, de uma só vez, quase sem valor, ao menos tornara-se muito difícil fazer uso delas para pagar as necessidades diárias da corte papal e dos seus membros. Certamente os cardeais, por exemplo, continuaram a ser nomeados conforme as igrejas tradicionais encarregadas, mas tinham de obter de outras fontes os seus vencimentos. Em adição a esse problema geral, Avinhão era uma construção gigantesca, erigida durante a primeira metade do século 14, incluindo o novo e austero palácio papal, que foi construído nessa forma que impressiona ainda hoje.

Tudo isso tinha de ser financiado solidamente. E os papas foram bemsucedidos nesse empreendimento. Porém, a necessidade, por parte da corte papal, de imensas quantidades de dinheiro estimulou as tendências de fiscalização de toda a Igreja para muito além do grau costumeiro. Os papas (e, especialmente, o Papa João XXII) foram bem-sucedidos na criação de instrumentos que permitiram impor esse fardo, não apenas para a pequena diocese de Avinhão, mas para toda a Igreja Cristã do Ocidente, especialmente por tomar parte num mercado centralizado de prebendas da igreja, ${ }^{9}$ uma tendência que seria levada a um ponto extremo mais tarde, durante o assim chamado Grande Cisma do cristianismo ocidental, quando as obediências aos dois e, mais tarde, mesmo aos três papas tinham de cumprir essa tarefa duas e três vezes, e isso de acordo com exigências de modo algum menores.

Os problemas logísticos e as suas soluções foram analisados por Stefan Weiss, Die Versorgung des päpstlichen Hofes in Avignon mit Lebensmitteln, Berlin 2002; sobre as fontes, cf. também Stefan Weiss, Rechnungswesen und Buchhaltung des Papsttums (1316-1378). Eine Quellenkunde (MGH, Hilfsmittel, 20), Hannover 2003.

8 Carl Gerold Fürst, Cardinalis. Prolegomena zu einer Rechtsgeschichte des römischen Kardinalseollegiums, München 1967; Stephan Kuttner, Cardinalis - The History of a Canonical Concept, in: Traditio 3 (1945), p. 129s., agora em Kuttner, Councils, Decretals and Collections of Canon Law ([Variorum] Collective Studies Series, CS 126), London 1980, nr. IX.

9 O mercado de prebendas na Idade Média Tardia, por parte da cúria romana, tem sido objeto de viva pesquisa e descrição. A título de exemplo, menciono apenas um resumo ensaístico: Brigide Schwarz, Römische Kurie und Pfründenmarkt im Spätmittelalter, in: Zeitschrift für Historische Forschung 20 (1993), p. 129-152. 
Essa fiscalização por parte da Igreja viria a ser apenas uma das mudanças realmente pesadas que o período de Avinhão da história da Igreja estava desenvolvendo. O segundo item de grande importância foi a centralização geral da Igreja no ofício papal, o assim chamado "papalismo" da estrutura da Igreja, que continuou no período de Avinhão e alcançou o vértice nas últimas décadas do século XIV. Pode-se até mesmo dizer que, fora dessa imaginação "papalista" centralizadora da constituição da Igreja, o assim chamado Grande Cisma do Ocidente, que eclodiu em $1378{ }^{10}$ não teria tido condições de persistir, uma vez que o Cisma em si estava enraizado no papalismo extremo do Papa Urbano VI, que não conseguiu administrar propriamente as relações difíceis de um papa reinante com os seus cardeais.

Mas, não desviemos a exposição, aqui, para uma história do Cisma. Para a teoria política, a situação do século XIV não era totalmente nova, mas estava ganhando um perfil mais agudo, dado que o conflito entre os dois poderes universais do Ocidente Latino Medieval da Europa, a luta entre o papa e o imperador, havia terminado durante o século XIII, não pela vitória de um dos dois lados, mas sim por mera exaustão. Certamente, o papa poderia ter pensado que permanecia como o vencedor no campo de batalha, dado que o imperador tinha retirado o seu campo de ação para os seus próprios domínios, especialmente para a Alemanha, ${ }^{11}$ enquanto a Itália, em meados do século XIV, estava quase abandonada por Carlos IV como um campo de políticas formativas de seus interesses. Assim, o papa foi deixado como a última força universal, ou melhor, como uma força com ambições universais. Mas, os reinos europeus, incluindo o império, não mantiveram em absoluto obediência fiel às intenções políticas papais. As diferenças e os conflitos entre a cúria papal em Avinhão e as cortes específicas dos reis europeus se tornaram, ocasionalmente, acentuadas, sem levar, ao mesmo tempo, a conseqüências dramáticas tais como as mostradas pelo conflito entre o Papa Bonifácio VIII e o Rei Filipe, o Belo, da França. ${ }^{12}$ Em adição a isso, o soberano alemão, Luís da Baviera, teria de sofrer com a luta contínua com os papas de Avinhão, durante o seu reinado na primeira metade do século (1316-1347). ${ }^{13}$ Mas, na segunda metade do século XIV, não houve mais nenhum rei europeu deposto por um papa de Avinhão. Os

10 Genèse et débuts du Grand Schisme d'Occident (Colloques Internationaux du CNRS, 586), Paris 1980.

11 Uma introdução ao campo sensível da teoria política, tocado por esses fatos, foi feita por Jürgen Miethke, Lupold von Bebenburg, Kanonistisches Staatsdenken in der Krise des Reichs, in: Lupold von Bebenburg. Über die Rechte von Kaiser und Reich, lateinisch und deutsch, übersetzt von Alexander Sauter, hrsg. und eingeleitet von Jürgen Miethke (Bibliothek des Deutschen Staatsdenkens, 14), München 2005.

12 Jean Favier, Philippe le Bel, Paris 1978; Joseph Reese Strayer, The Reign of Philip the Fair, Princeton N. J. 1980; mais resumidamente Jürgen Miethke, Philipp IV. der Schöne (1285-1314), in: Die französischen Könige des Mittelalters, hrsg. Joachim Ehlers, Heribert Müller, Bernd Schneidmüller, München 1996, p. 202-230, 399-401.

13 Cf. Heinz Thomas, Ludwig der Bayer (1282-1347), Kaiser und Ketzer, Regensburg und Graz-WienKöln 1993. 
métodos utilizados na primeira metade do século não mais poderiam ser aplicados na segunda parte do mesmo.

Durante o século XIV, os problemas das estruturas internas dos reinos foram ganhando mais e mais atenção. A concentração de poder na corte do rei e a centralização da jurisdição e da legislação fizeram progresso em diversas partes da Europa, na França, na Inglaterra, na Boêmia, mesmo em partes da Alemanha, onde, normalmente, nem o rei nem o imperador traziam à maturação a construção do estado, mas sim os príncipes locais do reino. Em especial, os príncipes eleitores estavam ganhando força e criando estruturas de estado dentro dos seus principados. Na França e na Inglaterra, foram primeiramente os problemas de dinastia que chamaram a atenção dos reis e dos seus conselheiros, desde o momento em que a mudança do último rei capetiano, Carlos IV, "o Belo" († 1328), para a linhagem afiliada dos Valois tinha sido decidida por ações resolutas do novo rei, Filipe VI, que conseguiu excluir todas as outras reivindicações ao trono e instalar a si mesmo como o inquestionado rei da França.

Entretanto, o Rei Eduardo III, da Inglaterra, não estava disposto e desistir dos seus direitos legais ao trono francês, que reclamara ter obtido por parte da sua mãe, uma filha do rei capetiano Filipe IV, o Belo, morto em 1314. Não precisamos descer até as questões difíceis das relações entre os diferentes reivindicadores do trono francês nem até o assunto complicado da Loi Salique ou Lex Salica, isto é, a preferência da herança patrilinear sobre a relação "feminina". Filipe VI era neto do Rei Filipe III, o rei capetiano pai de Filipe IV, e o era mais exatamente por seu pai, o irmão de Filipe IV, Carlos de Valois. Por sua vez, Eduardo III era o filho de uma filha de Filipe IV, Isabela, que era casada com o Rei Eduardo II, da Inglaterra. No final, o nó de problemas e de complicações de longa duração, que já tinha obscurecido a história da Inglaterra e da França desde a conquista normana da Inglaterra no século XI e certamente desde os tempos do erguimento do "império anglonormano", no século XII, se desfez em 1337, com o irrompimento da assim chamada "Guerra dos Cem Anos", que duraria por mais de um século, até 1453. Todo o conflito entre a Inglaterra e a França foi, ao final, um sinal de uma crise de longue duree ${ }^{14}$ para ambos os reinos envolvidos na guerra.

Não temos como entrar nos detalhes dessa dificuldade e dessa guerra, que durou gerações e gerações, cuja unidade e duração por tantas décadas foram reconhecidas já mesmo por alguns contemporâneos. O final foi uma separação mais clara dos dois reinos, França e Inglaterra, e um certo isolamento da Ilha Britânica, ainda que o rei da Inglaterra tenha usado, até o ano de 1802, nos seus atos formais, o título de "rei da França". Desde meados do século XV, França e Inglaterra estavam separadas definitivamente (com a exceção de Calais, que permaneceu nas mãos dos ingleses até meados do século XVI). Essa separação foi preparada durante toda a longa extensão da interminável guerra e é uma das razões

14 Isto é, de "longa duração". N. do T. 
para uma concentração mais estrita da vida intelectual inglesa sobre as questões britânicas, e a dos franceses sobre as questões francesas.

Podemos verificar isso em cada um dos lados do canal. Na França, havia, nos inícios da grande guerra, um rei muito ativo, a saber, Carlos V, "le Sage" (13641380) - qualificação essa que não deveríamos traduzir muito apressadamente por "o Sábio", mas de preferência por "o Letrado". Ele apoiou as correntes de centralização dos poderes reais, ao concentrar na sua corte um grupo brilhante de intelectuais de primeira, homens da universidade, treinados e formados como teólogos, filósofos e juristas, que estavam grandemente ocupados em agrupar as tradiÇões da sabedoria aprendida para o benefício do reino da França. ${ }^{16}$ É muito significativo que havia toda uma série de traduções de textos clássicos da língua erudita do latim para o francês vernacular, que teve de ser polido e ampliado, aguçado e tornado mais flexível, pela invenção uma série de novas palavras ou de noções modificadas e fixadas de modo original, uma verdadeira diversão para os filólogos e especialistas em lingüística, nas línguas românicas de hoje. ${ }^{17}$ Para a realidade da segunda metade do século XIV, essas traduções foram muito importantes. Elas deram uma nova chance aos leigos, aos nobres não-letrados ou semiletrados das cortes dos príncipes ou dos prelados, e de outros lugares, que não eram capazes de ler em latim. Eles podiam, agora, ser instruídos, pelas suas próprias leituras, com os tesouros da sabedoria tradicional e dos esforços teóricos do passado, que significavam alguma vantagem nas trevas daqueles tempos.

Mais uma vez, não é possível entrar em detalhes. Pode ser suficiente mencionar apenas alguns daqueles nomes e das suas traduções, com o intuito de indicar os esforços combinados da corte real. Havia o Maître des Requêtes ${ }^{18}$ (desde 1373) da residência real, em Châtelet, a saber, Raoul de Presles, o Jovem († 1382), ${ }^{19}$ um filho bastardo de um Clerc du roi ${ }^{20}$ erudito e Avocat du roi ${ }^{21}$ de mesmo nome († 1327), que tinha, então, introduzido o seu filho na jurisprudência, enviara o mesmo para estudar na Faculdade de Direito de Orléans e estabelecera-o na corte real. Raoul de Presles, o Jovem, tinha escrito primeiramente um Compendium morale de re publica (isto é, "Um compêndio moral sobre a política") e, em seguida, um verdadeiro rol de traduções, entre outras uma tradução da obra De civitate Dei, de Agostinho, e de tratados escritos durante a luta entre o Rei Filipe, o Belo, e o Papa Bonifácio VIII, do início do século, como, por exemplo, a Quaestio inter

15 Com toda justiça, a exposição de Jeannine Quillet escolheu o seguinte título: Charles V, le roi lettré. Essai sur la pensée politique d'un règne, Paris 1984.

${ }^{16}$ Sobre isso, chama a atenção, por último, Jacques Krynen, L'empire du roi, Idées et croyances politiques en France, XIII - XV' siècle (Bibliothèque des Histoires), Paris 1993.

${ }_{17}$ Cf., por exemplo, Serge Lusignan, Parler vulgairement. Les intellectuels et la langue française aux XIII et XIV siècles (Études médiévales), Paris 1986.

18 Isto é, "mestre de requisições". N. do T.

19 Cf. Robert Bossuat, Raoul de Presles, in: Histoire Littéraire de la France, Bd. 40, Paris 1974, p. 111 180, resumido por Elisabeth Lalou in: Lexikon des Mittelalters 7 (1995), p. 190s.

${ }^{20} \quad$ Isto é, "clérigo do rei". N. do T.

21 Isto é, "advogado do rei". N. do T. 
clericum et militem ${ }^{22}$ e a questão Rex pacificus Salomon. ${ }^{23} \mathrm{E}$ ele não era, de forma alguma, um solitário na corte francesa. Havia também o doctor utriusque iuris ${ }^{24} \mathrm{e}$ preletor na Faculdade de Direito da Universidade de Paris, a saber, Évrart de Trémaugon, ${ }^{25}$ o qual também, desde 1374, era um Maître des Requêtes do rei e, mais tarde, por proteção real, se tornou bispo de Dol (na Bretanha). Évrart tinha estudado direito em Bolonha, na Itália, com o famoso jurista João de Legnano, e foi comissionado pelo rei para escrever uma grande compilação sobre questões políticas, intitulada Somnium viridarii (completada em 1376), bem como a tradução para a língua do Rei Carlos V, feita pelo próprio autor, intitulada Songe du Vergier (completada em 1378). Em ambas as versões, está inserida uma grande quantidade de comentários eruditos à lei, em latim, bem como questões e tratados, excertos de polêmicas do tempo de Filipe, o Belo, e também das Octo quaestiones de Ockham ou do Defensor pacis de Marsílio de Pádua, constituindo, obviamente, uma grande coleção enciclopédica de textos importantes, no interesse do poder do rei, no seu reino. Como foi dito, primeiramente escrito em latim (1376), o apanhado inteiro do material foi transformado e traduzido, dois anos mais tarde (1378), para o francês. O empreendimento todo teve um bom destino, especialmente a versão francesa. Ela chegou até nós em 23 manuscritos (em adição, sabemos de mais dez manuscritos perdidos ou não encontrados hoje). Uma edição moderna, em quatro volumes magníficos, foi publicada em Paris há alguns anos, uma edição de ambas as versões, latina e francesa. ${ }^{26}$

Por último, mas não de menor importância, temos de mencionar Nicolau Oresme, um teólogo da Universidade de Paris, que também morreu como bispo: ele se tornou bispo de Lisieux (na Normandia), em 1377, e faleceu em 1382. Nicolau foi chamado, num dicionário moderno, de "one of the most important thinkers in natural sciences in the Medieval West". ${ }^{27}$ Como autor político, ele é famoso pelas suas traduções da Ethica e da Politica de Aristóteles, do latim para o francês. ${ }^{28}$ Essas versões foram algo como traduções comentadas, uma vez que não se

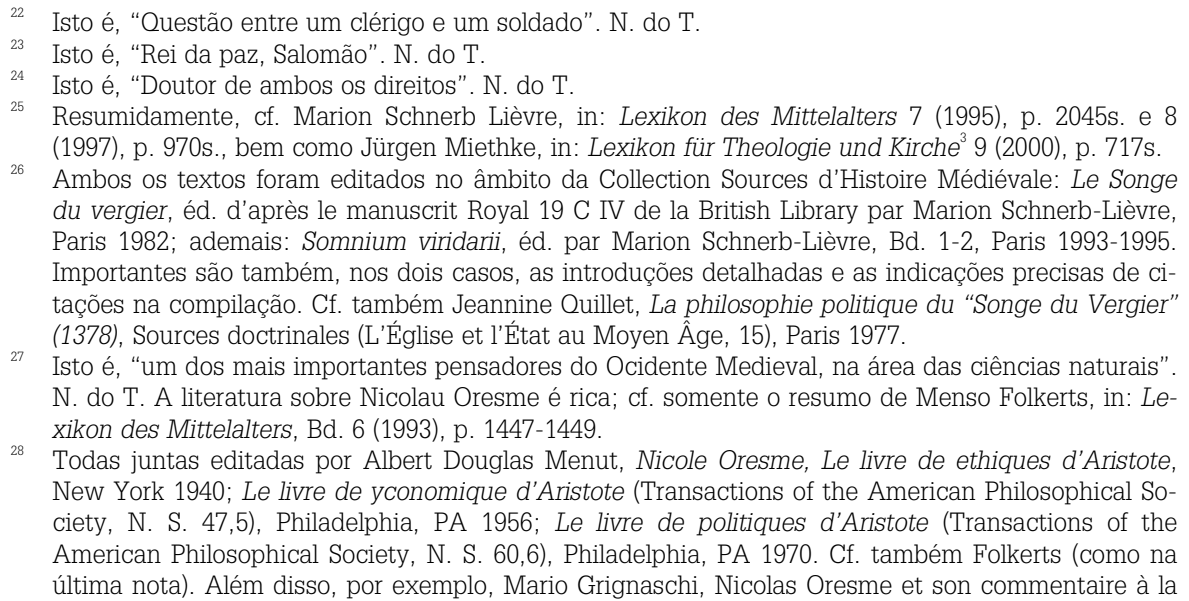
du vergier, éd. d'après le manuscrit Royal 19 C IV de la British Library par Marion Schnerb-Lièvre, Paris 1982; ademais: Somnium viridarii, éd. par Marion Schnerb-Lièvre, Bd. 1-2, Paris 1993-1995. Importantes são também, nos dois casos, as introduções detalhadas e as indicações precisas de citações na compilação. Cf. também Jeannine Quillet, La philosophie politique du "Songe du Vergier" (1378), Sources doctrinales (L'Église et l'État au Moyen Âge, 15), Paris 1977.

27 Isto é, "um dos mais importantes pensadores do Ocidente Medieval, na área das ciências naturais". N. do T. A literatura sobre Nicolau Oresme é rica; cf. somente o resumo de Menso Folkerts, in: Lexikon des Mittelalters, Bd. 6 (1993), p. 1447-1449.

${ }_{28}$ Todas juntas editadas por Albert Douglas Menut, Nicole Oresme, Le livre de ethiques d'Aristote, New York 1940; Le livre de yconomique d'Aristote (Transactions of the American Philosophical Society, N. S. 47,5), Philadelphia, PA 1956; Le livre de politiques d'Aristote (Transactions of the American Philosophical Society, N. S. 60,6), Philadelphia, PA 1970. Cf. também Folkerts (como na última nota). Além disso, por exemplo, Mario Grignaschi, Nicolas Oresme et son commentaire à la 
contentaram com uma equação do texto latino com um discurso em francês, mas tentaram explicar essas linhas num raciocínio individual, nas margens ou entre as linhas.

O objetivo de todas essas tarefas, e de outras similares, não foi o de ser uma coleção histórica de textos antigos, ou a modo de antiquário; antes, todos esses autores e tradutores tentaram, decididamente, dar apoio à "reforma do reino". O clamor por uma séria reformatio regni ${ }^{29}$ fora anunciado vivamente desde as primeiras décadas do século e foi levado adiante especialmente depois da derrota do exército francês em Poitiers (1356), onde o rei francês, João, o Bom, foi capturado pelos ingleses. Por décadas, a política francesa esteve ocupada em negociar e arrecadar a grande quantidade de benefícios que os ingleses queriam obter. O rei e a sua corte tentaram, depois desse período, estabelecer um controle real do conselho do rei por sobre o reino inteiro, incluindo o rendimento de taxas oriundo do mesmo. Esse foi um processo constante, que durou por várias décadas. Os intelectuais na corte do rei e dentro do conselho do rei se preocuparam muitos em unir-se a esses esforços, juntando a isso as suas próprias ocupações eruditas.

Do outro lado do canal, na Inglaterra, havia obviamente um outro clima, tal como podemos adivinhar já no que diz respeito à diferente situação. Os ingleses haviam vencido a Batalha de Poitiers, e, pelas próximas décadas, os seus esforços militares pareceram sair vitoriosos dentro da grande batalha. Mas, mesmo na Inglaterra é possível encontrar, nesses tempos, um pensamento relacionado aos problemas específicos do reino da Inglaterra. Mas, as questões levantadas na Inglaterra não foram direcionadas às estruturas constitucionais do reino. As tradições teológicas e eclesiásticas de chamar todos os cristãos à penitência tinham força suficiente para produzir um chamado amplo para reformar a própria vida, por meio da volta aos deveres originais dos cristãos.

Devemos ter tudo isso em mente, caso quisermos entender as intenções e a importância das doutrinas de João Wyclif. João Wyclif, ${ }^{30}$ nascido em torno de 1330,

Politique d'Aristote, in: Album Helen Maud Cam, Louvain/Paris 1960, p. 95-151; Jeannine Quillet, La philosophie politique du "Songe du Vergier" (1378), Sources doctrinales (L'Église et l'État au Moyen Âge, 15), Paris 1977, p. 123-167; Susan M. Babbitt, Oresme's "Livre de Politiques" and the France of Charles V (Transactions of the American Philosophical Society, N. S. 75,1), Philadelphia, PA 1985. Sobre as idéias de Nicolau Oresme acerca de uma reforma do reino, cf. sobretudo Jacques Krynen, Aristotélisme et réforme de l'État, en France, au XIV ${ }^{e}$ siècle, in: Das Publikum politischer Theorie im späteren Mittelalter, hrsg. Jürgen Miethke (Schriften des Historischen Kollegs/Kolloquien, 21), München 1992, p. 225-236. Cf. também Jacques Krynen, L'empire du roy, Idées et croyances politiques en France, XIII -XV siècle (Bibliothèque des Histoires, 1993), passim, em especial p. 419-432 (cf. também p. 111-124 e 550 ad ind.).

29 Isto é, "reforma do reino". N. do T.

30 Resumidamente, Katherine Walsh, Wyclif, John, in: Lexikon des Mittelalters 9 (1998) p. 391-393; cf. também as apreciações feitas por Lowrie John Daly, The Political Theory of John Wyclif, Chicago 1962; Anthony Kenny, Wyclif, Oxford 1985; a importante coletânea: Wyclif and his Time, ed. Anthony Kenny, Oxford 1986. As dificuldades de deduzir a teoria política de Wyclif a partir da sua eclesiologia foram apontadas por Francisco Bertelloni, Implicaciones politicas de la eclesiologia de Wyclif, in: Patristica et Mediaevalia 15 (1994), p. 44-58. Resumidamente, Jürgen Miethke, Las ideas políticas de la Edad Media, Traducción del alemán de Francisco Bertelloni, Buenos Aires 1993. Interessante também é a comparação com as posições críticas à Igreja de Jan Hus, por Alexander 
morreu como sacerdote de uma pequena paróquia de Lutherworth (Lincolnshire), em 1384. Ele tinha sido forçado a ir de Oxford para lá, pelo fato de ser suspeito de heresia; mas, no seu período de vida, os procedimentos da Igreja e da corte real contra a possível heresia e para o controle da fé não chegaram ao final. Nesse sentido, Wyclif morreu sem ter sido condenado definitivamente. Wyclif tinha tido uma carreira rica, angariou uma série de prebendas ao longo da sua vida. Temos o relato de que ele ficou desapontado quando, em 1373, não teve sucesso em tornar-se bispo de Worcester. Mas, ele não era oriundo da alta nobreza, portanto não é preciso entender isso como uma verdadeira negligência. A sua carreira universitária foi impecável, mesmo que só possamos segui-la, na maioria dos casos, pelas posições que ele ocupou em diversos colleges de Oxford, enquanto a seqüência dos seus escritos, de quantidade impressionante, ainda tem de ser esclarecida. ${ }^{31}$ Em 1356, em meados dos seus vinte anos, encontramo-lo como bacharel de artes e ocupante do cargo de assistente, no Merton College; em 1360, Wyclif contava como Mestre do Balliol College, mas abandonou este cargo um ano depois. Em 1363, iniciou o estudo de teologia. Em 1365, foi apontado pelo arcebispo de Cantuária, Simon Islip, para a posição de diretor do Canterbury College. Esta era uma escola que, originalmente, congregava monges beneditinos e mestres seculares. Mas, o arcebispo tentou converter a escola numa instituição voltada estritamente para teólogos seculares, e Wyclif parece ter sido escolhido por essas razões. Mas, quando o arcebispo morreu de modo prematuro, antes de ser capaz de finalizar a sua tarefa, o seu sucessor, Simon Langham, pôde reverter esse plano, ao expulsar os mestres seculares. Wyclif resistiu a esses planos e, junto com os seus mestres seculares companheiros, apelou contra essa decisão do arcebispo junto ao papa de Roma, em Avinhão, permanecendo na escola, a qual abandonou, junto com os mesmos mestres, somente três anos mais tarde, quando o papa, na sua decisão final, não lhe deu razão. Não é em absoluto inverossímil que a amarga oposição que Wyclif mostrou, mais tarde, contra a vida monástica e a hierarquia eclesiástica, incluindo o papa, pode ter se originado dessas experiências negativas, na sua própria ação judicial junto à cúria. Há um oponente contemporâneo se insinuando por detrás dessa conexão de motivos, mas o próprio Wyclif não nos oferece afirmações claras e unívocas sobre esse assunto.

Posteriormente, Wyclif viveu a maior parte do tempo no Queen's College, em Oxford, obteve o seu bacharelado em teologia em 1369 e mais tardar em 1373 foi promovido a magister theologiae..$^{32}$ A sua produção literária é muito profícua. As

Patschovsky, Ekklesiologie bei Jan Hus, in: Lebenslehren und Weltentwürfe im Übergang vom Mittelalter zur Neuzeit. Politik - Bildung - Naturkunde - Theologie, hrsg. von Hartmut Boockmann, Bernd Moeller, Karl Stackmann (Abhandlungen der Akademie der Wissenschaften in Göttingen, III.179), Göttingen 1989, p. 370-399.

31 Um panorama sistemático dos escritos latinos foi oferecido por Williel R. Thomson, The Latin Writings of John Wyclyf. An annotated catalog, in part from the notes of the late S. Harrison Thomson (Subsidia Mediaevalia, 14), Toronto 1983. Naturalmente, o debate sobre isso continua desde então. Falta um panorama desse tipo no que diz respeito aos escritos ingleses.

32 Isto é, "mestre de teologia". N. do T. 
suas obras foram impressas, desde o final do século XIX, em duas séries diferentes, as Obras Latinas de um lado, as Obras Inglesas de outro. Mas, até hoje a edição ainda não está totalmente completa, depois, portanto, de mais de um século. Toda a sua carreira universitária é acompanhada por escritos sobre temas "dos artistas", isto é, sobre questões lógicas, epistemológicas e filosóficas em geral. Como bacharel em teologia, ele escreveu um comentário compreensivo sobre todos os livros da Bíblia (Postilla super totam bibliam). ${ }^{33} \mathrm{Na}$ última década da sua vida, escreveu especialmente sobre a reforma da igreja e problemas sociais do reino. Como reformador, Wyclif tentou fazer dos ingleses cristãos melhores: este era o seu objetivo, e não escrever uma teoria política melhor.

Não é possível descrever em detalhes, aqui, as suas diferentes doutrinas políticas, nem cronologicamente nem nos vários acentos que Wyclif deu a elas, nos diferentes momentos da sua vida. Apenas tentarei oferecer algumas linhas básicas das suas argumentações. Mesmo nos seus escritos tardios, não é a intenção de Wyclif construir uma teoria política. Durante todo o tempo da sua vida, ele foi um teólogo (ou estava se tornando um teólogo na universidade). Ele tinha como meta a reforma da igreja, como muitos dos seus contemporâneos, mas perseguiu esse alvo com diferentes objetivos atuais diretos. De qualquer modo, o seu entusiasmo fervente nesse sentido permaneceu o mesmo durante toda a sua vida. O eco que ele encontrou para o seu chamado à reforma da igreja e da vida do seu tempo é, simultaneamente, característico para os efeitos dos professores da universidade dentro da sociedade na Idade Média Tardia.

Quais eram os seus principais argumentos, nos seus escritos políticos? Apenas tentaremos oferecer as linhas gerais do seu pensamento, e não as diferenciações dos seus escritos. Wyclif escreveu os seus tratados na língua latina erudita e no inglês vernacular, mesmo se a assim chamada Bíblia de Wyclif, uma tradução completa da Bíblia, não parte da sua pena, mas das atividades de alunos e de lollardos. O seu pensamento político estava centrado em torno da igreja, a igreja não como a comunidade dos fiéis, mas como a comunidade dos redimidos. Wyclif está seguindo estritamente Santo Agostinho, quando se mostra convencido de uma predestinação real daqueles redimidos que são a igreja real. Deus mesmo predestinou, desde a eternidade, todos os homens que serão redimidos no final dos tempos, quando do juízo final. A sua presciência é desde os tempos eternos. Os teólogos da escolástica, desde gerações, haviam trabalhado os modos de pensar corretamente tal presciência divina e a predestinação. ${ }^{34}$ Todos eles tentaram combinar onisciência divina dos futura contingentia ${ }^{35}$ com a liberdade e a respon-

\footnotetext{
33 A sua obra exegética é discutida, por exemplo, por Beryl Smalley, Wyclif's Postilla on the Old Testament and his Principium, in: Oxford Studies presented to Daniel Callus (Oxford Historical Society, N. S. 16), Oxford 1964, p. 253-296. A obra exegética de Wyclif, como um todo, é interpretada por Gustav Adolf Benrath, Wyclifs Bibelkommentar (Arbeiten zur Kirchengeschichte, 36), Berlin 1966 (= Theologische Habilitationsschrift Heidelberg 1964).

${ }^{34}$ A questão "de futuris contingentibus" é um famoso tópico de disputas filosóficas medievais, e não pode ser discutida aqui.

35 Isto é, "eventos" ou "acontecimentos futuros contingentes". N. do T.
} 
sabilidade humana pelas suas próprias ações. Para Wyclif, estava havendo um problema mais prático acerca da obra de bem-estar espiritual da igreja: o próprio Deus sabe, desde a eternidade, de todos os seres humanos particulares predestinados, mas os seres humanos, nos seus labores durante a vida, não têm certeza se são praedestinati et praescitit ${ }^{36}$ para céu ou inferno. Eles conseguirão sabê-lo somente quando do juízo final. Ninguém tem quaisquer percepções acerca da sua predestinação específica. Pois assim como os praesciti são capazes de pecar, e como os condenados podem fazer obras meritórias em momentos da sua vida, assim também é necessário ter em mente essa diferença entre vida meritória e estar predestinado à redenção eterna.

Sob essas condições, é muito difícil descobrir o que poderia ser a igreja real. A igreja poderia ser a comunidade daqueles que estão, no presente momento, no estado da graça. Entretanto, no final, essa comunidade poderia ser, sem exceção, uma comunidade de pessoas de boa vontade subjetiva, que não são, porém, predestinadas por Deus, mas condenadas ao inferno. Portanto, essa igreja das pessoas no estado da graça não pode ser a igreja real, o corpus Christi místico ou a santa igreja católica que confessamos no Credo Apostólico. Caso também se identifique a igreja com o conjunto daqueles que são predestinados, junto com aqueles que estão, no momento presente, no estado da graça, essa comunidade não pode preencher plenamente as exigências da igreja católica real, mas somente em parte, porque, incluída nessa comunidade, há um certo número de pessoas definitivamente condenadas. Parece claro que a igreja não pode ser senão a comunidade dos predestinados como um todo inteiro.

Essa acepção faz da igreja algo como uma entidade cuja forma real está esperando pelo juízo final escatológico futuro. A igreja se torna um fenômeno exclusivamente da história da salvação e está excluída da vida histórica humana. A percepção de que a igreja não é acessível para o conhecimento e a observação humana normal, porque Deus somente conhece quem é um membro real dela, tem fortes conseqüências. Trata-se de um ponto-chave na argumentação política e social de Wyclif. A igreja real na sua realidade escatológica não pode ser formalmente representada por nenhuma organização humana, seja qual for. Tampouco há uma relação consistente e estável de preparação entre qualquer organização do mundo e essa igreja escatológica e, num sentido especial, real. O cabeça da igreja é, definitivamente, o próprio Cristo, como é dito claramente no Novo Testamento. Sobre a terra não existe nenhum cabeça humano, nem um sacerdote nem mesmo o papa podem reivindicar ser tal cabeça. Wyclif está negando, por esta tese, a teoria dos canonistas, que tinham visto no papa romano o caput secundarie, isto é, o cabeça da igreja na terra num sentido secundário. Isso havia sido formulado mais tardar desde o século XII. ${ }^{37} \mathrm{O}$ motivo de Wyclif para esse desvio radical face

Isto é, "predestinados e pré-conhecidos". N. do T.

Mencione-se, em especial, Huguccio de Pisa; cf., por exemplo, Brian Tierney, Foundations of the Conciliar Epoch (Cambridge Studies in Medieval Life and Thought, II.4) [11956], edição ampliada (Studies in the History of Christian Thought, 81), Leiden (etc.) 1998. 
ao pensamento tradicional é, mais uma vez, a observação de que apenas no juízo final ficará claro quem foi predestinado e pertence à igreja verdadeira.

Enquanto essa qualificação da igreja verdadeira e real parece ser, de algum modo, a conseqüência de certas posições na teologia e na escatologia, as teorias de Wyclif com respeito à sociedade e política mundanas são mais complicadas, mesmo que estejam ligadas muito de perto a essas acepções básicas. Desde o início da década de 1370, Wyclif vinha escrevendo o seu tratado De civili dominio, ${ }^{38}$ baseado fortemente nas polêmicas contra os mendicantes e, especialmente, contra posições franciscanas escritas uma geração atrás pelo mestre secular de Oxford, Ricardo FitzrRalph, mais tarde arcebispo de Armagh, na Irlanda, o assim chamado "Armacanus". ${ }^{9}$ Wyclif está seguindo as linhas de Agostinho, novamente, quando declara que um homem no estado de pecado não tem nenhum direito de governo ou propriedade, de nenhum tipo de dominium (isto é, domínio, governo ou propriedade), enquanto todo ser humano no estado da graça é o senhor de tudo, como a própria Bíblia afirma (cf. 1 Cor 2.15).

Essa afirmação radical não é sem precedentes no século XIV. O papalista radical Egídio Romano havia escrito, no seu panfleto radical De ecclesiastica potestate (formulado na corte de Bonifácio VIII, no ápice da luta entre o papa e o rei da França, em torno de 1302), que somente as pessoas justas poderiam reivindicar dominium, segundo aquelas declarações escriturísticas; mas, para Egídio Romano, a justiça era definida, não pela predestinação ou pelo estado da graça, mas pelo fato de ser cristão e batizado e, por isso mesmo, pelo fato de ser sujeito ao papa. Egídio Romano tinha concluído que uma legitimação explícita ou implícita pela igreja se fazia necessária para todo governo legítimo dos príncipes. ${ }^{40}$ Wyclif está indo muito mais longe. Ele está muito distante de quaisquer reivindicações institucionais para a hierarquia da Igreja na terra. Está exclusivamente interessado na relação de indivíduos com as instituições sociais, qualificada pela própria situação dos indivíduos na sua perspectiva escatológica. A sua conclusão é breve: um governante que se encontra no estado da graça governa com direito - e, correspondentemente, o dono de uma propriedade que se encontra no estado da graça está com justiça de posse dos seus pertences -, mas um governante ou um dono de propriedade que se encontra no estado de pecado perde totalmente os seus direitos, ao menos aos olhos de Deus.

Essa posição trabalha com dois diferentes níveis de argumentação. O direito natural e o conseqüente deste, o dominium civile, têm de ser cuidadosamente

${ }^{38}$ Cf., por exemplo, De ecclesia, ed. Johann Loserth, London 1886; De dominio divino, ed. Reginald L. Poole, London 1890; sobretudo De dominio civili, ed. J. Loserth, R. L. Poole, F. D. Matthew, London 1880.

${ }^{39}$ Cf., em especial, Katherine Walsh, Richard FitzRalph in Oxford, Avignon and Armagh. A Fourteenth Century Scholar and Primate, Oxford (etc.) 1981.

40 Cf., em especial, Wilhelm Kölmel, Regimen Christianum. Weg und Ergebnisse des Gewaltenverhältnisses und des Gewaltenverständnisses (8. bis 14. Jahrhundert), Berlin 1970; cf., por exemplo, Jürgen Miethke, Ai confini del potere. Il dibatito sulla potestas papale da Tommaso d'Aquino a Guglielmo d'Ockham, traduzione di Cinzia Storti, prefazione, consulenza e revisione di Roberto Lambertini (Fonti e ricerche, 19), Padova 2005, p.106s. 
distinguidos do domínio evangélico. Esta distinção é de algum modo tradicional na teoria escolástica. Ela é correspondente à distinção entre pecado e rompimento da lei. Quem ocupa pela força uma terra alheia está de posse dela apenas pelo direito natural de ocupação, enquanto o dono, que foi privado pelo possessor, mantém o dominium civile. Somente se o detentor do dominium civile se encontra no estado da graça ele mantém também o domínio evangélico.

A transmissão de senhorio de um possuidor para outro e, com isso, a fundação do domínio sobre seres humanos ou propriedades de coisas, de acordo com Wyclif, não é possível apenas por seres humanos. A ordem do mundo dada por Deus está sempre envolvida. Há, portanto, também uma possibilidade de perder 0 próprio senhorio. Se o senhorio humano na esfera feudal pode ser perdido por felonia, de acordo com as leis feudais humanas, o quão mais o senhorio que está fundado na ordem de Deus pode ser perdido por felonia diante de Deus, isto é, pelos pecados?

O ser humano no estado da graça tem o seu senhorio dado por Deus, não isolado, para si mesmo, mas junto com todos os outros seres humanos que partilham com ele do estado da graça. Essa é a razão para a existência de deveres estritamente obrigatórios a todos os possuidores e senhores de usar a sua propriedade ou o seu domínio de uma maneira adequada. O ser humano é obrigado a usar o seu senhorio de modo correto. A pessoa rica que abusa da sua propriedade está perdendo, por esse pecado, o senhorio, ele não é mais o senhor de acordo com a lei evangélica. Wyclif também pode dizer isso de um modo mais tradicional: ele está abusando da propriedade do pobre. O mesmo deve ser dito sobre o domínio. Um senhor obteve o seu domínio por Deus. Portanto, o domínio pode durar apenas no estado da graça. Quem permanece no estado de pecado perde o seu direito de domínio, pelas mesmas razões por que perde a sua propriedade.

Isso parece deduzido de modo bastante claro. Mas, nas circunstâncias práticas, é difícil imaginar que essas posições se realizem. Como se pode reconhecer que se está no estado da graça e como se pode reconhecer que uma outra pessoa está no estado da graça? Aqui, Wyclif não ofereceu respostas isentas de ambigüidade. Ele nem mesmo poderia dar tais respostas não ambíguas, uma vez que a sua reserva escatológica faz com que isso seja, ao final, algo impossível. Portanto, é até possível achar nos seus escritos a repetição de uma longa admoestação, visando à humildade cristã que os cristãos deveriam expressar até mesmo diante de um senhor ou de um rei tirânico. Cristo tinha sido obediente diante de Herodes e diante de Pilatos, e ensinou aos seus discípulos dar o tributo aos romanos. Os cristãos deveriam imitar esses exemplos. Parece claro que Wyclif não foi um revolucionário que tentou depor reis e barões e subverter a ordem política. Em minha opinião, parece muito mais provável que ele estava interessado, acima de tudo, em pregar a penitência e uma percepção moral aos senhores. Eles deveriam, primeiramente, alinhar o seu comportamento aos seus deveres.

Em todo caso, se é impossível dizer se um homem está definitivamente no estado da graça, porque apenas Deus pode saber disso exatamente, é muito mais fácil dizer se um homem está no estado de pecado mortal. Isso, afinal, está defini- 
do por uma longa tradição, e também Wyclif não mudou essas condições. Estar em pecado mortal significa, para ele, jogar fora o direito de senhorio. Isso é válido em ambos os casos, ou seja, toca o prelado da Igreja do mesmo modo que o senhor secular. Mas, isso foi mais diretamente aplicável para os eclesiásticos e clérigos do que para os príncipes seculares. Wyclif, também, tinha aguçado a sua argumentação principalmente naquela direção. De qualquer modo, podemos concluir, a partir dessa linha de argumentação, em primeiro lugar a sua preocupação com a reforma da igreja. E, em segundo lugar, também o seu chamado para uma igreja pobre deve ser visto numa conexão estreita com essas exigências: uma igreja pobre de pessoas pobres, não sobrepujada com riquezas seculares e poder feudal. Esta havia sido uma exigência aberta dos movimentos de pregação do século XI até o século XIV. A eclesiologia mendicante, ${ }^{41}$ que foi atacada tão duramente por Wyclif alhures, estava, quanto a esse aspecto, em plena concordância com as idéias de reforma do nosso teólogo de Oxford. Ele jamais identificou a organização eclesiástica do seu próprio tempo com a igreja real de Cristo. Portanto, não estava disposto a aplicar as promessas de Deus feitas ao seu povo simplesmente para a Igreja Romana ou ao papa e à hierarquia eclesiástica. No seu senhorio, o príncipe secular e o prelado eclesiástico são imagens de Deus somente quando e se eles dominam de acordo com a ordem de Deus. O seu domínio ou o seu lugar hierárquico dentro da igreja é legitimado por Deus apenas, não por meio de qualquer instituição da sociedade ou por meio da igreja como instituição. Os prelados mais elevados da Igreja, incluindo o próprio papa, não sabem antes do juízo final se estão predestinados ou não e, por isso mesmo, se são membros da verdadeira igreja de Cristo ou não, mesmo que, num determinado momento, possam se encontrar no estado da graça. Se não o sabem, questionar sobre isso é obviamente supérfluo.

Para Wyclif, as diferenças entre a hierarquia eclesiástica e os príncipes seculares eram meramente secundárias. Mas, para os seus contemporâneos, o seu olhar aguçado para os abusos eclesiásticos o tornou atrativo para muitas pessoas diferentes. O próprio Wyclif deve ter sido um pregador bastante impressionante e um panfletista muito capaz. Assim, durante o tempo de sua vida, obteve apoio, não apenas dos círculos universitários e dos estudantes, mas também da corte do rei até quase o ápice da sua hierarquia, ou seja, os filhos do rei, os príncipes João de Gaunt e Eduardo, o fabuloso "Príncipe Negro" da Guerra dos Cem Anos. ${ }^{42}$ Mas,

${ }^{41}$ Cf. Yves Marie Joseph Congar, L'Eglise de Saint Augustin à l'époque moderne (Histoire des Dogmes, III.3), Paris 1970; Y. M. J. Congar, Aspects ecclésiologiques de la querelle entre mendiants et séculiers dans la seconde moitié du XIII siècle et le debut du XIV siècle, in: Archives d'Histoire Doctrinale et Littéraire du Moyen Age t. 28, a. 36 (1961), p. 35-159; Jürgen Miethke, Die Rolle der Bettelorden im Umbruch der politischen Theorie an der Wende zum 14. Jahrhundert, in: Stellung und Wirksamkeit der Bettelorden in der städtischen Gesellschaft, hrsg. von Kaspar Elm (Berliner Historische Studien, 3 = Ordensstudien, II), Berlin 1981, p. 119-153.

42 Cf. Michael Wilks, Reformatio regni. Wyclif and Hus as Leaders of Religious Protest Movements, in: Schism, Heresy and Religious Protest, ed. Derek Baker (Studies in Church History, 9), Cambridge 1972, p. 109-130; sobretudo, porém, idem, Royal Patronage and Anti-Papalism from Ockham to Wyclif, in: From Ockham to Wyclif, ed. Anne Hudson, M. Wilks (Studies in Church History, Subsidia 
Wyclif alcançou amplas camadas do povo também. Os seus seguidores, tanto na Inglaterra quanto no continente, constituíram um movimento destacável, que duraria por um longo período após a sua morte. Acreditamos saber agora que os assim chamados "lollardos" ${ }^{\prime 3}$ não são imediatamente oriundos de Wyclif pessoalmente, mas parece claro que são, nas suas doutrinas principais, seguidores dos ensinos de Wyclif, e seguidores especialmente - talvez com algum grau de mauentendimento - da sua pregação em Oxford, na década de 1370 e no início da década de 1380. Os lollardos, pode-se dizer, constituem o único movimento declarado como heresia pela igreja oficial que obteve uma ampla audiência na Inglaterra medieval tardia. Certamente, o seu surgimento tornou a situação mais difícil para o próprio Wyclif, nos seus últimos dias. Mas, por outro lado, os lollardos podem demonstrar, pela sua existência mesma, que Wyclif tinha uma grande influência na prática de vida dos seus seguidores. A sua peculiaridade erudita e uma crítica popular da estrutura da igreja, bem como da vida diária dos seus tempos, formaram com ele um amálgama inescrutável de grande atração.

Não somos obrigados nem a entrar nos detalhes da pregação dos lollardos, ${ }^{44}$ nem a fazer um escrutínio da real influência pessoal do teólogo João Wyclif sobre a famosa "guerra dos camponeses" de 1382, influência essa que pode ter sido, sob certo aspecto, um elemento catalisador para esse levante revolucionário que ameaçou o reinado de Ricardo II. Se quisermos fazer uma afirmação breve, para resumir a importância de João Wyclif para o desenvolvimento geral do pensamento político, podemos afirmar que a tendência de territorialização do pensamento político na Idade Média Tardia apareceu também na escatologia generalizada de João Wyclif. Nesse sentido, ele partilhou de uma tendência universal. Isso parece ser válido, mesmo que ele tivesse como objetivo cada ser humano, e não apenas os ingleses. Além disso, parece ter sido exatamente essa territorialização que foi de forte apelo aos contemporâneos de Wyclif. A forma especial dessa crítica fundamental à ordem política existente, em nome de um princípio universal e da própria vontade e presciência de Deus, tornou a sua mensagem aplicável à totalidade da sua audiência.

A perseguição de Wyclif como herege não cuidou de criticar esses itens gerais do seu pensamento, mas questões muito especiais da sua teoria do conhecimento e da sua teoria da eucaristia. Quando finalmente 62 artigos, selecionados de 260 sentenças "errôneas", tiradas dos seus escritos, foram condenados no Concílio de Constança, exatamente no dia em que o mestre de teologia tcheco Jan Hus foi condenado à morte e queimado diante dos portões da cidade, o rei inglês não teve pressa em deixar escavar os ossos do reformador, que tinha morrido em 1384, em Lutherworth, há mais de trinta anos, para jogá-los fora. Num primeiro

5), Oxford 1987, p. 135-163. Cf. também William Farr, John Wyclif as a Legal Reformer (Studies in the History of Christian Thought, 10), Leiden 1974.

${ }^{4}$ Cf. Anne Hudson, The Premature Reform; resumidamente, Anne Hudson, Lollarden, in: Lexikon des Mitelalters 5 (1991), p. 2091-2093.

${ }^{4}$ Textos expressivos se encontram, agora, sobretudo in: English Wiclyffite Sermons, ed. Anne Hudson and Pamela Olive Elizabeth Gradon, vol. I-III (Oxford English Texts), Oxford 1983-1990. 
momento, eles não o fizeram. Isso só foi feito quase duas décadas mais tarde, em 1428, quando o arcebispo de Cantuária exigiu que o rei e a sua corte fossem finalmente obedientes ao decreto do concílio. ${ }^{45}$ No século XVI, João Wyclif foi nomeado pelos protestantes como um dos Testes veritatis, isto é, uma das "testemunhas da verdade". ${ }^{46}$ Mas, isso já é uma outra história.

Traduzido do inglês por Roberto Hofmeister Pich

45 De modo detalhado, cf. Jeremy I. Catto, Wyclif and Wycliffism at Oxford, 1356-1430, in: The History of the University of Oxford, Volume II: Late Medieval Oxford, ed. J. I. Catto and Ralph Evans, Oxford 1992, p. 263-280.

${ }^{46}$ Cf., em especial, Mathias Flacius Illyricus, Catalogus testium veritatis, qui ante nostram aetatem reclamarunt papae, Basel 1556 [também Straßburg 1562]. Sobre este autor, por último, cf. Martina Hartmann, Humanismus und Kirchenkritik. Mathias Flacius Illyricus als Erforscher des Mittelalters (Beiträge zur Geschichte und Quellenkunde des Mittelalters, 19), Stuttgart 2001. 